\title{
CORRESPONDENCE
}

Correspondents are asked to be brief

\author{
All Change

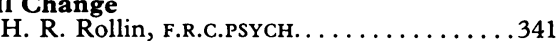 \\ Psychiatry in the Soviet Union \\ W. von Baeyer, M.D.................341 \\ Distribution and Supervision of \\ Oral Contraceptives \\ Sir Norman Talbot, F.R.C.o.g. . . . . . . . . 342 \\ First-aid Treatment of Poisoning and \\ Cardiac Arrest \\ P. A. B. Raffle, F.R.C.P., and others... . . . 342 \\ Two-phase Blood Culture System \\ J. E. Sippel, PH.D., and others.... . . . . 342 \\ Place of Diagnostic Radiology in \\ Medicine \\ J. O. M. C. Craig, F.F.R. . . . . . . . . . . 343 \\ Comparison between Free Thyroxine Index \\ and Effective Thyroxine Ratio \\ A. M. B. Boss, B.sC., and D. Kingstone,

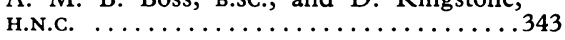 \\ New Curriculum \\ M. F. Green, M.R.C.P. . . . . . . . . . . 344
}

Hyperglycericacidaemia with Hyperglycinaemia: A New Inborn Error of Metabo-

lism

N. J. Brandt, M.D., and others.......... 344

Uticillin

M. J. Bendall, M.R.C.P.; H. R. Ingham,

M.R.C.PATH., and J. B. Selkon, M.R.C.PATH...34

tatus of Ward Sisters

I. Price, S.R.N.

Ethics and Halothane

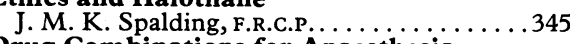

rug Combinations for Anaesthesia

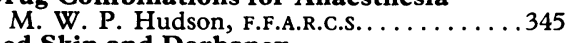

ed Skin and Dorbanex

H. Ippen, M.D. .

Inappropriate $A D H$ Secretion in

Chest Disease

J. B. Myers, M.B.

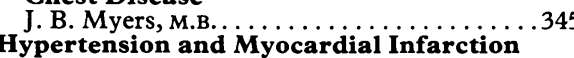

K Seedand Myocardial Infarction

Variability in Response to Drugs

J. K. W. Morrice, F.R.C.PSYCH...

Medical Management of Heartburn

K. S. Mullard, F.R.C.S.............. 346

Anonymous Appointments

M. Prendergast, M.B. . . . . . . . . . . . 346

Economies in the N.H.S.

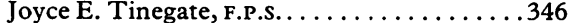

Review Body

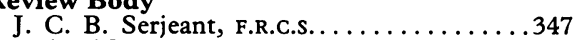

Dentists' Pay

L. B. Lux, L.D.S.R.C.s..

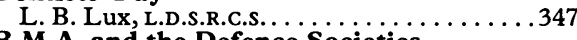

G. Societies

G. E. Crawford, M.R.c.G.P...........347

N.H.S. Superannuation

R. J. Earlam, F.R.C.s.; R. D. G. Peachey,

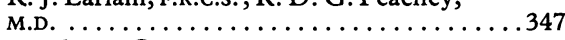

Consultant Contract

J. S. Brown, M.B., D.M.R.D. . . . . . . . . 348

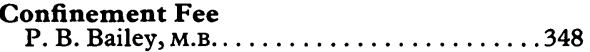

Locums and Agencies

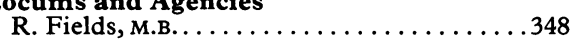

Rural Practices Fund

H. K. Davison, M.B.............. 348

N.H.S. Contraceptive Services

M. V. Smith, M.F.c.M. . . . . . . . . . 348

\section{All Change}

SIR,-May I be allowed to sketch a face of our National Health Service-one oddly enough, that has nothing at all to do with money?

In 1948 I was appointed a consultant psychiatrist. I had at that time two burning enthusiasms. One was for the N.H.S. itself; the other was to extend psychiatry into the general hospitals. But which? The deciding factor was, I learnt to my cost, the catchment area of the parent mental hospital.

In the original allocation of catchment areas Horton Hospital, Epsom, my parent hospital, was allocated that part of the metropolis in which St. Stephen's Hospital, Fulham, was located. I was instructed to start a clinic at that hospital and in 1948 I did so, gleefully and enthusiastically. Some months later we were informed that our catchment areas had been changed and that Horton was to take over, inter alia, the Hampstead area and part of Merton. Believing as I did then in the omniscience of bureaucrats and their divine right to order these things, I respectively touched my forelock, packed up at St. Stephen's and in 1949 began to plough my lonely furrow at New End Hospital, Hampstead, and the Nelson Hospital, Wimbledon. In 1960 the chaps with the maps decided that the Royal London Homoeopathic Hospital should be linked with Horton Hospital and it was suggested that I attend there on an "as required" basis. Obediently I did so, but not for long. The same chaps had had a second think and had decided that the Homoeopathic be linked with another hospital. I was asked to cease to attend.

However, the New End and Nelson clinics flourished, particularly the former, where facilities existed for expansion. Before not too long the services of two additional consultant colleagues were necessary in order to cope with the work. Together we offered a service to the hospital itself, to our colleagues in other medical disciplines, and to the general practitioners in the district. In
1970 Horton's catchment area was changed again. Virtually overnight the service that had been built up over a period of two decades at New End collapsed. There were protests from colleagues at the hospital, from the G.P.s, and from the patients themselves, but all to no avail.

The bureaucrats now decided in their strange, arbitrary way that Horton must take over the psychiatric needs of part of the Borough of Richmond. This time I was detailed to start up at St. Mary's Hospital, Hampton. With perhaps less glee and less enthusiasm I did so. It is easy to demonstrate that there is always an untapped need for psychiatric services in any community; the clinic itself and the domiciliary service grew and I began to enjoy working with my new patients and colleagues.

It is hard to believe that one can have the ground cut from beneath one's feet for a fourth time in a single career but, lo and behold, the bureaucrats decided that it was imperative that catchment areas must be realigned. The same protests from the same sources that had been made at New End were echoed, but the decision was final and at the end of September this year I ceased to attend St. Mary's.

The picture I have drawn is, I think you will agree, unattractive and unacceptable. The wart which disfigures it most, in my opinion, is the assumption by the powers that be that hospitals in the N.H.S. can be treated like shops in a multiple chain-store organization. They seem to have forgotten, if they ever knew, that the practice of medicine, and that of psychiatry in particular, has to do with people and that it has to do with patient-doctor relationships, some of which have had to be built up over a period of years. Doctors and their patients, may I remind them, are not packets of soapflakes that can be moved from one shelf to the next shelf or from one shop to the next shop with impunity.

Do I sound disenchanted, disillusioned, or even a trifle paranoid? I am. I bloody well am.-I am, etc.,

Horton Hospital,

HENRY R. ROLLIN

Epsom, Surrey

\section{Psychiatry in the Soviet Union}

SIR,-Professor G. Morozov's letter (6 July, p. 40) discussing Western criticisms of the misuse of forensic psychiatry for the purpose of persecution of political dissenters is most timely. He deals particularly with the critical remarks of Professor J. K. Wing (9 March, p. 433), and refers in the third paragraph of his letter to German, Swiss, Austrian, and French schools of psychiatry whose views, according to him, are closer to the Soviet school than are those of Professor Wing. As a considerable part of my work has been concerned with problems of forensic psychiatry (including the problem of responsibility in cases of mentally ill litigants who, even in the West, can be regarded as a kind of dissenting group) I would like to discuss the points raised by Professor Morozov.

(1) The psychiatric assessment of dissenters in the Soviet Union is nat limited to a diagnosis of schizophrenia, where the criteria are admittedly ill-defined. Thus in the case of the psychiatric detention of General Grigorenko, who was recently released, schizophrenia was not regarded as the disorder for which compulsory psyahiatric treatment was carried out over many years. I quote from the diagnostic summary of the psychiatric report ${ }^{1}$ of which Professor Morozov was a cosignatory: "Grigorenko is suffering from a mental illness in the form of a pathological (paranoid) development of the personality, with the presence of reformist ideas that have appeared in his personality, and with psychopathic features of the character and the first signs of cerebral arteriosclerosis" (p. 70). It can be seen that in the Soviet Union the psychiatric assessment of responsibility and 
the grounds for treatment do not depend primarily on the diagnosis. The line of argument in the Grigorenko report shows that the decisive issue is whether an aocused person possesses the necessary critical faculties and self-oontrol for his opinions and actions or whether, owing to certain psychiatric abnormalities, this is not the case. Hence differences of opinion over the diagnostic limits of a schizophrenic illness are not of critical importance.

(2) In the Grigorenko report the term "paranoid development" and "delusional ideas" are used where German-trained psychiatrists would use, at most, the term "over-valued ideas" (überwertige Ideen) (Wernicke). These are ideas that are comprehensible in the context of a person's life or the historical circumstances in which he lives and which are maintained with strong emotion and persistence even against considerable opposition in the surrounding world. From a strictly psychiatric standpoint, however, it is not possible to distinguish between these so-called over-valued ideas and moral and religious beliefs maintained with persistence and strong affective colouring. They are dependent on the philosophical or political system of values which determine the assessment of such ideas.

(3) Strongly held beliefs and ideas, and the actions resulting from them, do not as such determine responsibility, since they have been based on comprehensive grounds and held with normal conviction. There are, of course, exceptions in which such comprehensible ideas arise from a clearly discernible illness, mostly schizophrenia, but these would have to be determined in each case separately. In the case of Grigorenko, as in other cases known in the West that may be less well documented, the "reformist ideas" cited do not impress as manifestations of a mental illness. They correspond to a widely held humanist and liberal tradition which, though not officially recognized in the Soviet Union, is surely well known there from historical experience and from relations with foreign countries. The views held by Grigorenko and likeminded people contain nothing which in themselves can be considered absurd, bizarre, or egocentric as would be the case, for instance, in a paranoid schizophrenic delusion. In the documents that have reached the West it is striking that the forensic diagnosis of psychiatric disturbances rests overwhelmingly on such "reformist ideas." Yet such ideas cannot be used as proof of a mental disturbance with however much determination and feeling they may be expressed.

(4) Criticism of psyohiatric reports on dissenters made in the Serbsky and other Soviet institutes rests less on the diagnostic category ascribed to each case-about which there may be disagreement-than on the arbitrary way in which the expression of such "reformist ideas" is equated with lack of critical faculties, responsibility, and self-control. Such reasoning is considered by the German school of psychiatry, as well as by all other schools, to be inadmissible because it supposes pathological disturbances of the intellect and behaviour which are not in themselves disturbed at the time of the incriminating act. This impression is particularly striking if one studies the documents ${ }^{1}$ more closely and analyses the reasoning behind them. Such an analysis forces one to suspect that assessments are not made on scientific and clinical grounds but are based on political and opportunist considerations. (5) The impression of poverty of psychiatric evidence cannot be erased by the proceedings at the conference at the Serbsky Institute in October 1973. This impression is strengthened after thorough study of the Bukovsky papers, ${ }^{1}$ which are now available in English, French, and German. The genuineness of these documents has never been questioned. Bukovsky, who for his courageous act was sentenced to a long term of imprisonment, has thus become a martyr to psychiatry for protesting, at the risk of his life and liberty, against these misuses. The same can probably be said of the Jewish Ukrainian psychiatrist Dr. Gluzman, who dared to subject the Serbsky Institute's psychiatric report on Grigorenko to criticism-whatever may have been said at the Serbsky Institute about the nonexistence of a psychiatrist of this name. It is not only to justify and pay homage to these courageous men but also to prevent further misuse of forensic Dsychiatry that psychiatris:s and their organizations in all coun ries should unite as never before to raise critical and accusing voices of warning more strongly and loudly than hitherto. No psychiatrist who has carefully and objectively studied the Bukovsky documents can fail to do this, either personally or through his professional organization.-I am, etc.,

University Psychiatric Clinic,

WALTER VON BAEYER Geidelberg

1 Committee on the Judiciary, U.S. Senate, Abuse of Psychiatry for Political Repression in the
Soviet Union. Washington, D.C., U.S. GovernSoviet Union. Wash
ment Printer, 1972.

Distribution and Supervision of Oral Contraceptives

SIR,-Dr. M. V. Smith and his distinguished cosignatories (19 October, p. 161) present a powerful consensus in favour of widening the range of those empowered to dispense oral contraceptives. While not questioning the need for some liberalization, I am unhappy about the extent of their proposal.

Like myself, many who work in the field of family planning believe that much can with benefit be delegated to the nursing members of the team, including the dispensing of resupply oral contraceptive packs. We do not all share the view that fitness and suitability for this method can be decided by other than a doctor, and preferably the family practitioner. Nor will the latter lightly abandon the advantages to the total care of their patients of periodic consultation and examination.

We are aware that there are those who would go even further than your correspondents-those who advocate the open sale of oral contraceptives across the counter, who would have technicians trained to insert intrauterine devices and even to perform vasectomy, and who decry the role of doctors in contraception. Unfortunately, their thesis is indirectly supported by those who for a variety of reasons regard family planning as outside the scope of normal medical practice.

One hopes that any decision to modify current regulations will be based upon a consideration of the balance of risks and benefits to our patients and upon a determination not to sacrifice standards of medical care and the doctor-patient relationship to political or financial expediency. Should it be decided to extend to nondoctor health personnel the right to dispense oral contraceptives under the supervision of a doctor, the responsibilities of the doctor and the role of the health personnel must be governed by a code of practice similar to that which governs the practice of midwives.-I am, etc.,

Fleet, Hants

NORMAN TALBOT

\section{First-aid Treatment of Poisoning and} Cardiac Arrest

SIR,-At a recent meeting we discussed the letters on "Danger of Saline Emetics in First Aid for Poisoning" from Drs. C. J. C. Roberts and M. J. Noakes (14 September, p. 683) and from Drs. $M$. Winter and D. J. E. Taylor (28 September, p. 801). On the evidence which has been presented to us it was decided that emesis contributes little to the first-aid treatment of poisoning. We therefore propose to recommend that at the next impression of our joint manual (third edition) the instruction to produce vcmiting should be omitted.

We are also recommending the omission of the instruction to thamp the chest repeatedly in cases of cardiac arrest because of the accumulating evidence that repeated "chest thumping" is of value only under hospital conditions. External cardiac compression should still be practised as recommended.-We are, etc.,

ANDREw RAFFLE
Chief Medical Officer,

H. R. F. MACDONALD Chief Medical Officer,
St. Andrew's Ambulance Association JOHN GRAY Chief Medical Officer,

\section{Two-phase Blood Culture System}

SIR,-In many developing countries where salmonellosis, brucellosis, and meningococcal disease are endemic oommercial blood culture systems are not readily available and preparation of similar systems requires equipment for carbon dioxide gassing not normally found in small hospital or field laboratories. Ox bile is excellent for isolation of salmonella, easy to prepare, and difficult to contaminate, but it is ineffective for isolating more fastidious species.

We have used a two-phase Castaneda bottle ${ }^{1}$ for routine blood culture. This system (TSA/Thio), which can be prepared in any laboratory equipped with an autoclave or pressure cooker, consists of a 4-oz $(113 \mathrm{~g})$ prescription bottle containing $30 \mathrm{ml}$ of trypticase soy agar (BBL) and $30 \mathrm{ml}$ of thioglycolate medium 135-C (BBL) with $1 \%$ sodium citrate as an anticoagulant. TSA/ Thio has the additional advantage of not requiring subculture to identify positive cultures since growth in the bottle is usually manifested by colony formation on the agar slant surface. The data in the table show that TSA/Thio is as effective in isolating salmonella, brucella, and meningococci as a 